\title{
Ni-Catalyzed Conversion of Enol Triflates to Alkenyl Halides
}

\author{
Julie L. Hofstra ${ }^{\dagger}$, Kelsey E. Poremba ${ }^{\dagger}$, Alex M. Shimozono ${ }^{\dagger}$, and Sarah E. Reisman*
}

\begin{abstract}
A Ni-catalyzed halogenation of alkenyl triflates was developed that enables the synthesis of a broad range of alkenyl iodides, bromides, and chlorides under mild reaction conditions. The reaction utilizes inexpensive, bench stable $\mathrm{Ni}(\mathrm{OAc})_{2} \cdot 4 \mathrm{H}_{2} \mathrm{O}$ as a pre-catalyst and proceeds at room temperature in the presence of sub-stoichiometric $\mathrm{Zn}$ and either cod or DMAP as a supporting ligand.
\end{abstract}

Alkenyl halides are versatile functional groups that can be used in a variety of carbon-carbon and carbon-heteroatom bond-forming reactions. For example, alkenyl halides are commonly used as substrates in transition metal-catalyzed cross-coupling reactions ${ }^{1}$ or are converted via metal-halogen exchange to nucleophiles for 1,2-additions to carbonyl compounds (Scheme 1). ${ }^{2}$ Furthermore, the alkenyl halide moiety appears in some natural products and bioactive molecules. ${ }^{3}$ Whereas acyclic alkenyl halides are easily prepared from the corresponding alkyne ${ }^{4}$ or aldehyde ${ }^{5}$ most cyclic alkenyl halides are synthesized from the corresponding ketone. The most direct method is the Barton reaction (and variations thereof), ${ }^{6,7}$ which proceeds through an intermediate hydrazone. These reactions are notoriously capricious: the formation of the requisite hydrazone can be challenging on sterically encumbered substrates and the halogenation step often produces mixtures of alkenyl halide isomers or dihalide side products. ${ }^{8}$

As a result, enol triflates, which can be prepared directly from cyclic ketones under either kinetic or thermodynamic control, have emerged as attractive "pseudohalides" for transition metal-catalyzed cross-coupling processes. Unfortunately, enol triflates cannot be directly converted to the corresponding alkenyllithium or alkenylmagnesium species commonly employed in 1,2-addition reactions. In cases where the Barton procedure to prepare the alkenyl halide is poor yielding, a multistep alternative is frequently employed: 1) conversion of the ketone to enol triflate, 2) conversion of the triflate to the alkenyl stannane, and 3 ) conversion of the stannane to the alkenyl halide. ${ }^{9}$ Direct, mild methods to convert enol triflates to alkenyl halides, without proceeding through

${ }^{[*]} \quad$ J. L. Hofstra ${ }^{[t]}$, K. E. Poremba ${ }^{[t]}$, A. M. Shimozono ${ }^{[t]}$, and Prof. S. E. Reisman

The Warren and Katharine Schlinger Laboratory of Chemistry and Chemical Engineering, Division of Chemistry and Chemical

Engineering, California Institute of Technology

Pasadena, CA 91125 (USA)

Email: reisman@caltech.edu

Homepage: http://reismangroup.caltech.edu

['] These authors contributed equally to this research and are listed alphabetically.

Supporting information for this article can be found under: LINK HERE organostannane intermediates, can streamline the preparation of these valuable synthons.

Indeed, Buchwald has reported a Pd-catalyzed reaction to convert alkenyl triflates to alkenyl bromides and chlorides; ${ }^{10}$ however, there are no examples of alkenyl iodide formation, and the reaction requires an expensive ligand, temperatures greater than $100{ }^{\circ} \mathrm{C}$, or additives such as fluoride salts or ${ }^{i} \mathrm{Bu} \mathrm{u}_{3} \mathrm{Al}$. These additives limit the functional group compatibility of the transformation, particularly with commonly used groups such as silyl ethers. More recently, Hayashi reported a Ru-catalyzed method to convert enol triflates to iodides, bromides, or chlorides that proceeds at ambient temperature; however, the requisite ruthenium catalyst is not commercially available and limited examples of alkenyl iodide formation are reported. ${ }^{11}$

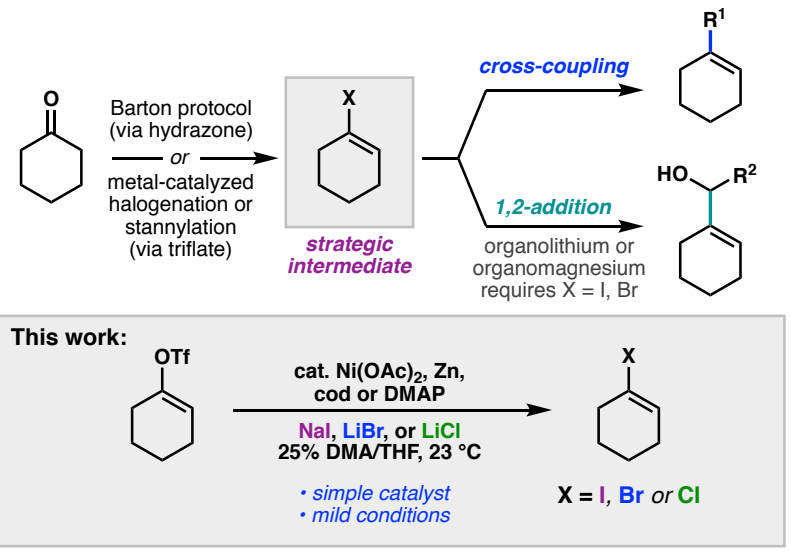

Scheme 1. Synthesis and utility of alkenyl halides.

During our investigations of Ni-catalyzed asymmetric reductive coupling reactions of alkenyl bromides, ${ }^{12}$ we observed an off-pathway halide exchange process that generated alkenyl chlorides and iodides. Whereas Nicatalyzed ary $\mathrm{l}^{13}$ and alkenyl halide exchange processes have been previously reported and extensively investigated, ${ }^{13 b}, 14$ development of the corresponding reactions of enol triflates have been limited to a single report describing bromination of dihydropyranyl enol triflates. ${ }^{15,16 a}$ Having observed promising reactivity with enol triflates in our investigation of asymmetric reductive coupling reactions, ${ }^{17}$ we hypothesized that an appropriate $\mathrm{Ni}$ catalyst and inexpensive halide salts might enable the direct conversion of alkenyl triflates to alkenyl halides under mild conditions. In this communication, we report the development of a Ni-catalyzed triflate-halide exchange (triflex) reaction, which provides access to alkenyl iodides, bromides, and chlorides in good to excellent yields (Scheme 1). 
Our reaction development began with enol triflate 1a, prepared in one step from menthone, with the goal of identifying general conditions that could provide the alkenyl iodide, bromide, or chloride simply by changing the halide salt. Initial optimization efforts using $\mathrm{Ni}(\operatorname{cod})_{2}$ as a catalyst revealed that a mixed DMA/THF solvent system and short reaction times were optimal, and that bidentate ligands (phosphine, amine, and pyridine) inhibited the reaction. ${ }^{18}$ Informed by these results, we screened a variety of $\mathrm{Ni}(\mathrm{II})$ pre-catalysts in combination with $\mathrm{Zn}^{0}$ and cod and ultimately found that $\mathrm{Ni}(\mathrm{OAc}) \cdot 4 \mathrm{H}_{2} \mathrm{O}$ afforded promising results across all three reactions. ${ }^{18}$ While $5 \mathrm{~mol} \%$ $\mathrm{Ni}\left(\mathrm{OAc}_{2}\right) \cdot 4 \mathrm{H}_{2} \mathrm{O}$ and longer reaction times appeared general for the bromination and chlorination reactions, the iodination required DMAP as a supporting ligand in order to obtain complete conversion (Table 1, entries 1 and 13). ${ }^{19}$ Moreover, although comparably high yields were obtained with various $\mathrm{Ni}$ loadings when 1a was used (Table 1, entries 1, 9, and 10), higher Ni loading (10 mol \%) and shorter reaction time $(6 \mathrm{~h})$ was deemed optimal in order to maximize conversion while minimizing protodetriflation across a variety of substrates. ${ }^{20}$

Table 1. Optimization of reaction conditions. ${ }^{\text {[a] }}$

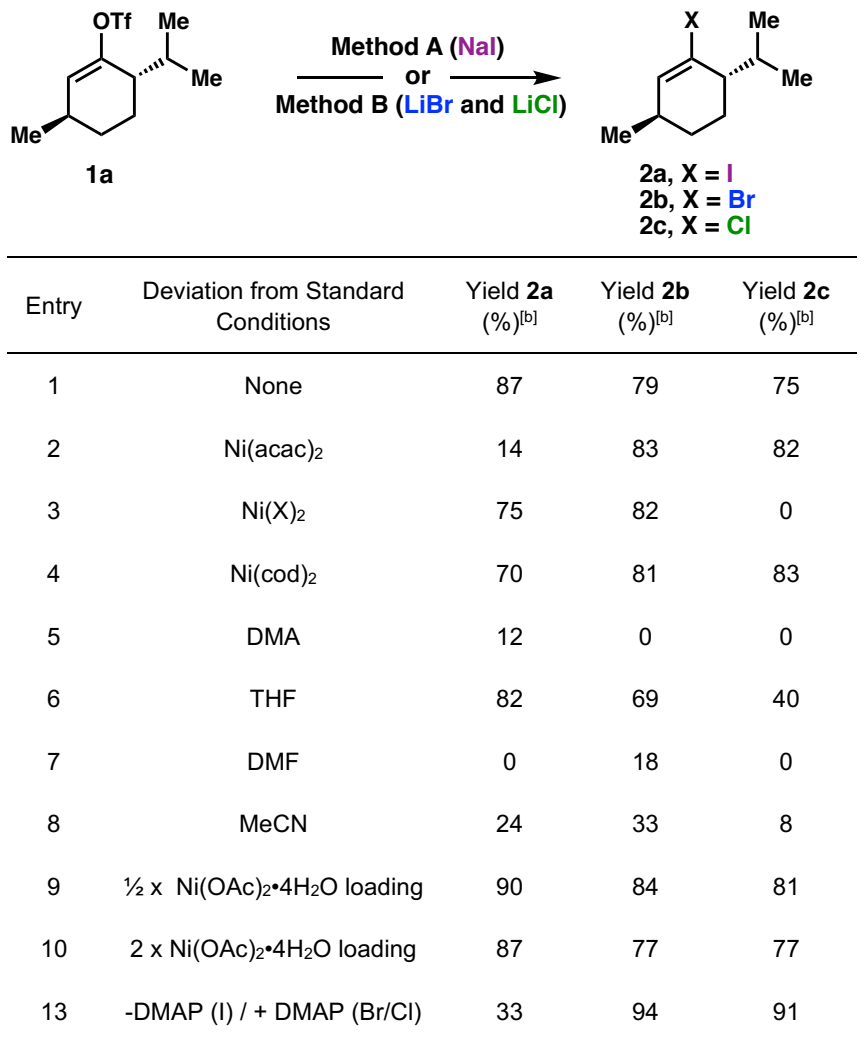

[a] Method A: Ni(OAc) $)_{2} \bullet 4 \mathrm{H}_{2} \mathrm{O}(10 \mathrm{~mol} \%), \mathrm{Zn}(20 \mathrm{~mol} \%)$, cod $(20 \mathrm{~mol} \%)$, DMAP $(20 \mathrm{~mol} \%)$, Nal (1.5 equiv), $25 \%$ DMA/THF $(0.25 \mathrm{M}), 23^{\circ} \mathrm{C}, 6 \mathrm{~h}$. Method B: $\mathrm{Ni}(\mathrm{OAc})_{2} \bullet 4 \mathrm{H}_{2} \mathrm{O}$ (5 mol \%), $\mathrm{Zn}(10 \mathrm{~mol} \%)$, cod (10 mol \%), $\mathrm{LiBr}$ or $\mathrm{LiCl}$ ( 1.5 equiv), $25 \%$ DMA/THF $(0.25 \mathrm{M}), 23{ }^{\circ} \mathrm{C}, 16 \mathrm{~h}$. Reactions conducted under inert atmosphere on $0.1 \mathrm{mmol}$ scale. [b] Determined by ${ }^{1} \mathrm{H}$ NMR versus 1,2,4,5-tetrachloronitrobenzene as an internal standard.

Having identified satisfactory reaction conditions, the substrate scope of the $\mathrm{Ni}$-catalyzed halogenation reaction was investigated (Table 2). The halide exchange was found to be compatible with a variety of common functional groups, including amines $(4)$, carbamates $(5,13)$, pyridines $(20)$, alkenes $(\mathbf{1 0}, \mathbf{1 2})$, esters $(\mathbf{1 9})$, ketals $(\mathbf{6}, \mathbf{1 4})$, and enones $(\mathbf{1 1})$. Dienyl halides could also be prepared in good yields, although the dienyl iodides 10 and 14 required longer reaction times and excess $\mathrm{Nal}$ in order to achieve high conversion. Chemoselective halogenation of the alkenyl triflate was observed in preference to aryl triflates $(\mathbf{1 5}, \mathbf{2 0})$, aryl chlorides $(9,21)$, and aryl boronates (22); however, competitive halide exchange was observed in the presence of aryl bromides and iodides. ${ }^{18}$

Although the Ni-catalyzed halogenation exhibits good functional group tolerance, the iodination, bromination, and chlorination did not perform equally well. In particular, the initial iodination conditions proved general for roughly half the substrates. In cases where the iodination was sluggish $(\mathbf{6}, \mathbf{8}$, 10, 11, 13-16), longer reaction times and increased concentrations of $\mathrm{Nal}$ improved conversions; however, the improved reactivity was often accompanied by increased amounts of reduction, ${ }^{20}$ and the alkene could be difficult to separable from the alkenyl iodides (8a, 10a, 11a, 13a, 15a). Thus, for a subset of these substrates $(10,11,13)$, use of $\mathrm{Ni}(\operatorname{cod})_{2}$ in conjunction with the enol nonaflate afforded access to the alkenyl iodides, which could be isolated without detectable quantities of corresponding alkene. ${ }^{16 \mathrm{~b}}$

In contrast, the bromination and chlorination reactions were generally more efficient and robust. For most substrates, complete conversions were achieved with lower Ni loading and without the need for DMAP, although DMAP provided improved yields in cases where incomplete conversion was observed with cod (14-16). In addition, for 1-arylvinyl triflates (19-22, Table 2) the use of $\mathrm{Ni}(\operatorname{cod})_{2}$ (method C) provided cleaner reaction profiles for the bromination and iodination. ${ }^{21}$

To better understand the Ni-catalyzed halogenation of enol triflates, and the iodination in particular, a series of mechanistic experiments were performed. $\mathrm{Ni}(\operatorname{cod})_{2}$ was used for these studies, since the reactions were homogeneous. The iodination of $1 \mathrm{a}$ exhibits an induction period at low $\mathrm{Ni}(\operatorname{cod})_{2}$ loadings (e.g. $0.5 \mathrm{~mol} \%, 1 \mathrm{~mol} \%$ ) (Scheme 2a). ${ }^{22}$ Plotting $V_{\max }$ vs. [Ni] revealed that the reaction has a positive-order dependence on [Ni] that negatively deviates from first order at higher [Ni], suggesting the formation of dimeric (or higher order) off-cycle species at higher $[\mathrm{Ni}] .{ }^{23} \mathrm{No}$ change in the rate of iodination of $1 \mathrm{a}$ is observed when the amount of $\mathrm{Nal}$ is increased beyond 1 equiv.

A crossover experiment was designed to evaluate the reversibility of alkenyl halide formation: treatment of a 1:1 mixture of 24-OTf and $\mathbf{2 5 -}-\mathrm{Br}$ with $\mathrm{Ni}(\operatorname{cod})_{2}(10 \mathrm{~mol} \%)$ in $1: 3$ DMA/THF at $23{ }^{\circ} \mathrm{C}$ resulted in complete recovery of 24-OTf and $25-\mathrm{Br}$, without detection of crossover products 25-OTf or 24-Br (Scheme 2b). Addition of 0.1 or 1.0 equiv $\mathrm{LiBr}$ resulted in conversion of $24-0 \mathrm{Tf}$ to $24-\mathbf{B r}$ in $10 \%$ and $90 \%$ yield, respectively; ${ }^{24,25}$ no 25 -OTf was detected at any point in either reaction. Monitoring the reaction by ${ }^{1} \mathrm{H}$ NMR confirms that no oxidative addition of 24-OTf occurs in the absence of halide salt. Subjection of alkenyl iodide $25-\mathrm{I}$ to $\mathrm{Ni}(\mathrm{cod})_{2}(10 \mathrm{~mol} \%)$ and metal triflate salts (e.g. NaOTf) did not result in enol triflate 
Table 2. Scope of alkenyl halides. ${ }^{[a]}$<smiles>CC(C)=C(O)I</smiles>

$\underset{\text { Method B }}{\stackrel{\text { Method } A(\text { NiBr }}{\longrightarrow} \text { and LiCl) }}$<smiles>[X]C(C)=C(C)C</smiles>

2-23
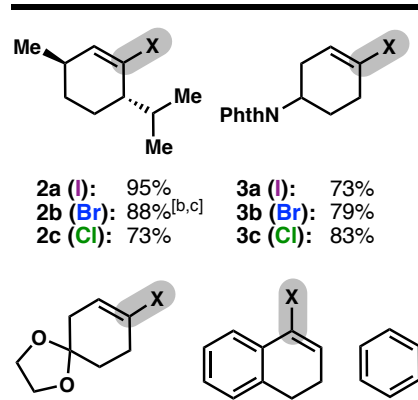<smiles>[X]C1=CCN(Cc2ccccc2)CC1</smiles>

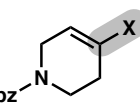

$\begin{array}{ll}\text { 3a (I): } & 73 \% \\ \text { 3b (Br): } & 79 \%\end{array}$ 3c (CI): $83 \%$

4a (I): $\quad 91 \%$ 4b (Br): $92 \%$

5a (I): $\quad 68 \%$ 5b (Br): $89 \%$ 5c (Cl): $87 \%$

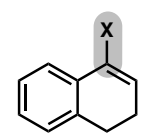<smiles>[X]C1=CC(P)Oc2ccccc21</smiles><smiles>[X]C1=CCC(c2ccc(Cl)c(Cl)c2)c2ccccc21</smiles>

6a (I): $\quad 82 \%$ [d] $\quad 7 a(l): \quad 83 \%$ $\begin{array}{ll}\text { 6b (Br): } 94 \% & 7 b(\mathrm{Br}): 94 \% \\ \text { 6c (Cl): } 88 \% & 7 \mathrm{c}(\mathrm{Cl}): 93 \%\end{array}$

\section{8a (I): $\quad(90 \%)^{[\mathrm{d}]}$} 8b (Br): $89 \%$
8c (Cl): $95 \%$

\section{9a (I): $77 \%$} 9b (Br): $92 \%$ 9c (Cl): $87 \%$<smiles>[X]C1=CC2=CC[C@@H](C(=C)C)C[C@]2(C)[C@H](C)C1</smiles><smiles>[X]C1=CCCC2=CC(=O)CCC12[M]</smiles>

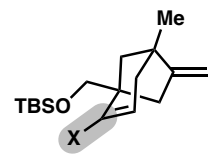

10a (I): $54 \% \%^{[\mathrm{e}, \mathrm{f}]}(70 \%)^{[\mathrm{d}]}$ 10b (Br): $84 \%$

11a (I): $53 \%\left[\%^{[\mathrm{e}, \mathrm{f}]}(70 \%)^{[\mathrm{d}]}\right.$ 11b (Br): $95 \%$

$2 a(\mathrm{l}): 91 \%$
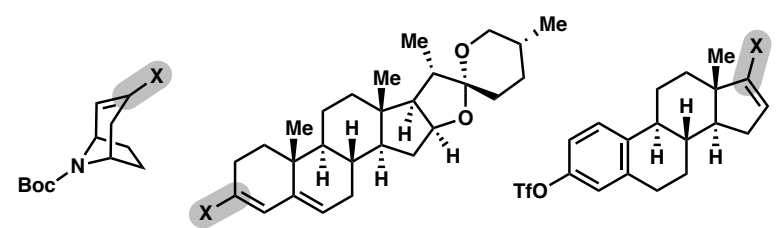

$$
\begin{aligned}
& \text { 13b (Br): } 94 \% \\
& 13 c(\mathrm{Cl}): 95 \%
\end{aligned}
$$

13a (l): $53 \%[\mathrm{e}, \mathrm{f]}](74 \%)^{[\mathrm{d}]}$<smiles>[X]C1=CC[C@@H]2[C@H](C)[C@H](C)[C@H]2[C@@H]2[C@@H](C)CC[C@H]12</smiles>

aa (l): $85 \%[\mathrm{~d}, \mathrm{~g}, \mathrm{~h}]$ 14b (Br): $93 \%[\mathrm{~b}, \mathrm{~g}, \mathrm{~h}]$ 14c (Cl): $83 \%[\mathrm{~b}, \mathrm{~g}, \mathrm{~h}]$

15a (I): $\quad(60 \%)^{[\mathrm{d}]}$ 15b (Br): 95\%[b,g] 15c (Cl): $90 \%{ }^{[b, g]}$ $\begin{array}{ll}\text { 16a (l): } & 62 \%[\mathrm{~d}] \\ \text { 16b (Br): } & 78 \% \text { [b] }\end{array}$ 16b (Br): $78 \%[\mathrm{~b}]$
16c (Cl): $75 \%$ [b]<smiles>[X]C(=C)c1ccc(O)nc1</smiles>

20a (I): $54 \%\left[\%^{[f]}\right.$ $20 \mathrm{~b}$ (Br): $80 \%$ [f] 17a (I): $89 \%$ 17b (Br): $93 \%$ 17c (Cl): $95 \%$<smiles>[X]C1=CCCCc2ccccc21</smiles>

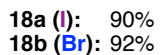
18b (Br): $92 \%$
18c (Cl): $88 \%$<smiles>[X]C(=C)c1ccc(Cl)c(F)c1</smiles><smiles>[X]C(=C)c1ccc([Hg][Hg])cc1</smiles><smiles>[X]C(=C)C12CC3CC(CC(C3)C1)C2</smiles>

21a (l): $69 \%[\mathrm{ff}]$
21b (Br): $73 \%[f]$ 22a (l): $68 \%$ [f] 22b (Br): $64 \%$ 23a (I): $86 \%$ 23b (Br): $88 \%$ 23c (Cl): $83 \%$ [a] Reactions conducted under inert atmosphere on $0.3 \mathrm{mmol}$ scale. Isolated yields ( ${ }^{1} \mathrm{H}$ NMR yield determined with internal standard). Method A: $\mathrm{Ni}(\mathrm{OAc})_{2} \bullet 4 \mathrm{H}_{2} \mathrm{O}(10 \mathrm{~mol} \%), \mathrm{Zn}(20 \mathrm{~mol} \%)$, cod $(20 \mathrm{~mol} \%)$, DMAP $(20$ mol \%), Nal (1.5 equiv), 25\% DMA/THF $(0.25 \mathrm{M}), 23{ }^{\circ} \mathrm{C}, 6 \mathrm{~h}$. Method B: $\mathrm{Ni}(\mathrm{OAc})_{2} \bullet 4 \mathrm{H}_{2} \mathrm{O}(5 \mathrm{~mol} \%), \mathrm{Zn}(10 \mathrm{~mol} \%)$, cod (10 mol \%), LiBr or LiCl (1.5 equiv), $25 \%$ DMA/THF $(0.25 \mathrm{M}), 23^{\circ} \mathrm{C}, 16 \mathrm{~h}$. [b] DMAP $(10 \mathrm{~mol} \%)$ instead of cod. [c] $5 \mathrm{mmol}$ scale. [d] 5 equiv $\mathrm{Nal}$ was used in the absence of cod, 36 $\mathrm{h}$ reaction time. [e] Enol nonaflate used. [f] Method C: $\mathrm{Ni}(\operatorname{cod})_{2}(10 \mathrm{~mol} \%)$, MX (1.5 equiv), $25 \%$ DMA/THF $(0.25 \mathrm{M}), 23^{\circ} \mathrm{C}, 16 \mathrm{~h}$. [g] $0.2 \mathrm{mmol}$ scale. [h] Conducted at $0.125 \mathrm{M}$. formation (Scheme 2c). ${ }^{26}$ Taken together, these results suggest that oxidative addition of the alkenyl triflate is irreversible, or that halide exchange for triflate in the oxidative addition complex is rapid and irreversible. In either scenario, the fact that the enol triflate is irreversibly consumed enables the reaction to proceed in good yield to the respective alkenyl halides. This is in contrast to Ni-catalyzed halide exchange reactions, which are thermodynamically driven equilibrium processes. ${ }^{13 \mathrm{~b}}$ For example, after $2 \mathrm{~h}$, an 85:15 mixture of 25$\mathrm{Br}: 25-\mathrm{I}$ is obtained for both the Ni-catalyzed reactions of $25-\mathrm{Br}$ with Lil, or $25-\mathrm{I}$ with $\mathrm{LiBr}^{18}$

Scheme 2. Mechanistic investigation. ${ }^{[a]}$

(a) Kinetic analysis
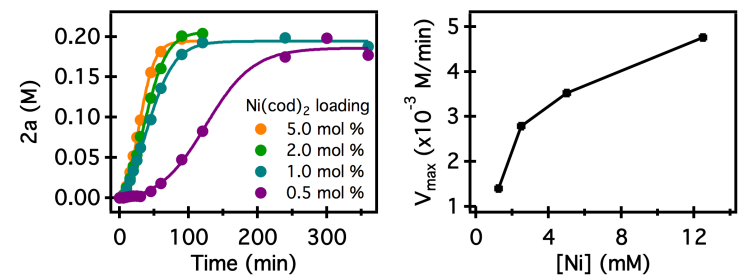

(b) Crossover experiment

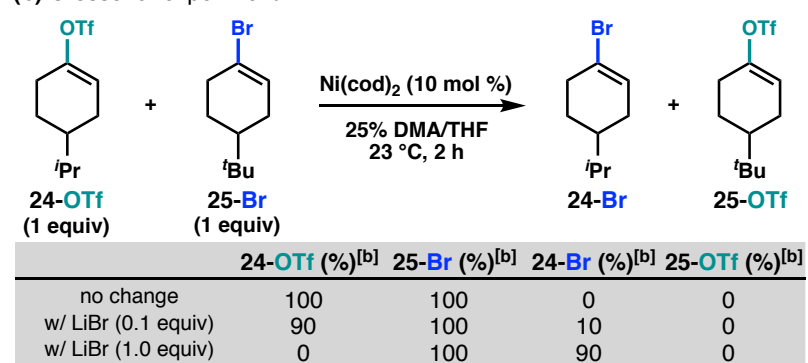

(c) Attempt to observe halide-triflate exchange.

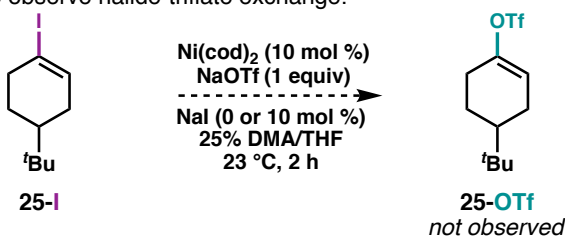

[a] Reactions conducted under inert atmosphere on $0.2 \mathrm{mmol}$ scale. [b] Determined by GC analysis versus undecane as an internal standard.

In conclusion, a mild Ni-catalyzed halogenation of alkenyl triflates has been developed. By modifying the halide salt, alkenyl iodides, bromides, or chlorides can be obtained using a simple, inexpensive catalyst system. These reactions proceed at room temperature, afford the alkenyl halides in good to excellent yields, and exhibit good functional group tolerance.

\section{Acknowledgements}

We thank the following Caltech staff for their help: Dr. Scott Virgil and the Caltech Center for Catalysis and Chemical Synthesis for access to experimental and analytical equipment; Dr. Mona Shahgholi and Naseem Torian for assistance with mass spectrometry measurements; and Dr. 
Paul Oyala for assistance with EPR experiments. We also thank Jordan C. Beck for assistance in the preparation of alkenyl triflates $\mathbf{1 e}$ and $\mathbf{1 k}$. Fellowship support was provided by the National Science Foundation (graduate research fellowship to J. L. H. and K. E. P, Grant No. DGE-1144469). S. E. R. is a Heritage Medical Research Institute Investigator.

1 (a) Metal-catalyzed Cross-Coupling Reactions; De Meijer, A., Diederich, F., Eds.; Wiley-VCH Verlag GmbH \& Co. KGaA: 2004; Vols. 1 \& 2. (b) K. C. Nicolaou, P. G. Bulger, D. Sarlah, Angew. Chem., Int. Ed. 2005, 44, 4442. ${ }^{2}$ M. Schlosser, Ed.; John Wiley \& Sons, Inc.: 2013.

${ }^{3}$ (a) G. W. Gribble, Springer-Verlag: Wien, Austria, 1996. (b) G. W. Gribble, Springer-Verlag: Wien, Austria, 2010. (c) G. W. Gribble, Mar. Drugs. 2015, 13, 4004.

${ }^{4}$ (a) D. W. Hart, T. F. Blackburn, J. Schwartz, J. Am. Chem. Soc. 1975, 97, 679. (b) H. C. Brown, C. Subrahmanyam, T. Hamaoka, N. Ravindran, D. H. Bowman, S. Misumi, M. K. Unni, V. Smayaji, N. G. Bhat, J. Org. Chem. 1989, 54, 6068. (c) F. Gao, A. H. Hoveyda, J. Am. Chem. Soc. 2010, 132, 10961. (d) M. R. Uehling, R. P. Rucker, G. Lalic, J. Am. Chem. Soc. 2014, 136, 8799. (e) J. Derosa, A. L. Cantu, M. N. Boulous, M. L. O'Duill, J. L. Turnbull, Z. Liu, D. M. De La Torre, K. M. Engle, J. Am. Chem. Soc. 2017, 139, 5183.

${ }^{5}$ (a) K. Takai, K. Nitta, K. Utimoto, J. Am. Chem. Soc. 1986, 108, 7408. (b) G. Stork, K. Zhao, Tetrahedron Lett. 1989, 30, 2173.

${ }^{6}$ (a) D. H. R. Barton, R. E. O'Brien, S. Sternhell, J. Chem. Soc. 1962, 470. Modified Barton procedure: (b) M. E. Furrow, A. G. Myers, J. Am. Chem. Soc. 2004, 126, 5436. (c) D. P. Ojha, K. R. Prabhu, Org. Lett. 2015, 17, 18. (d) A. Spaggiari, D. Vaccari, P. Davoli, G. Torre, F. Prati, J. Org. Chem. 2007, 72, 2216

7 The trisilylhydrazones can be converted directly to the corresponding alkenyllithium reagents. (a) J. E. Stemke, A. R. Chamberlin, F. T. Bond, Tetrahedron Lett. 1976, 34, 2947. (b) A. R. Chamberlin, J. E. Stemke, F. T. Bond, J. Org. Chem. 1978, 43, 147. For a review, see: (c) R. M. Adlington, A. G. M. Barrett, Acc. Chem. Res. 1983, 16, 55.

${ }^{8}$ For a discussion of the challenges associated with hydrazone synthesis, see ref $5 b$, and references found therein.

${ }^{9}$ For a recent example of this sequence in total synthesis, see: A. D. Huters, K. W. Quasdorf, E. D. Styduhar, N. K. Garg, J. Am. Chem. Soc. 2011, 133, 15797.

${ }^{10}$ (a) X. Shen, A. M. Hyde, S. L. Buchwald, J. Am. Chem. Soc. 2010, 132, 14076. (b) J. Pan, X. Wang, Y. Zhang, S. L. Buchwald, Org. Lett. 2011, 13, 4974.

${ }^{11}$ (a) E. Shirakawa, Y. Imazaki, T. Hayashi, Chem. Commun. 2009, 5088. (b) E. Imazaki, E. Shirakawa, R. Ueno, T. Hayashi, J. Am. Chem. Soc. 2012, 134, 14760.

12 (a) A. H. Cherney, S. E. Reisman, J. Am. Chem. Soc. 2014, 136, 14365. (b) N. Suzuki, J. L. Hofstra, K. E. Poremba, S. E. Reisman, Org. Lett. 2017, $19,2150$.

${ }^{13}$ (a) K. Takagi, N. Hayama, T. Okamoto, Chem. Lett. 1978, 191. (b) T. T. Tsou, J. K. Kochi, J. Org. Chem. 1980, 45, 1930.
Financial support from the NIH (R35GM118191-01) is gratefully acknowledged.

Keywords: nickel $\bullet$ halogenation $\cdot$ enol triflates $\cdot$ catalysis $\bullet$ alkenyl halides

${ }^{14}$ (a) K. Takagi, N. Hayama, S. Inokawa, Chem. Lett. 1978, 1435. (b) M. C J. M. Hooijdonk, T. H. A. Peters, S. F. Vasilevsky, L. Brandsma, Syn. Commun. 1994, 24, 1261. For reviews, see: (c) D. A. Petrone, J. Ye, M. Lautens, Chem. Rev. 2016, 116, 8003. (d) G. Evano, A. Nitelet, P. Thilmany, D. F. Dewez, Front. Chem. 2018, 6:114.

15 (a) J. E. Milne, K. Jarowicki, P. J. Kocienski, Synlett, 2002, 4, 607. (b) The authors note that chlorination and iodination is also feasible, but no yields are reported. Application of these conditions to substrate 1a provided products $\mathbf{2 a}, \mathbf{2} \mathbf{b}$, and $\mathbf{2 c}$ in $<10 \%$ yield. See the Supporting Information.

${ }^{16}$ (a) A Ni-catalyzed trifluoromethylthiolation of alkenyl triflates was recently reported: A. Dürr, G. Yin, I. Kalvet, F. Napoly, F. Schoenebeck, Chem. Sci. 2016, 7, 1076. (b) Use of an enol nonaflate in place of the enol triflate improved the yield for one example in the above report.

17 J. L. Hofstra, A. H. Cherney, C. M. Ordner, S. E. Reisman, J. Am. Chem. Soc. 2018, 140, 139.

18 See Supporting Information.

19 The precise role of DMAP remains unclear. (a) Org. Lett. 2017, 19, 2118. (b) J. Org. Chem. 2018, 83, 14036.

${ }^{20}$ Protodetriflation was observed in up to equimolar amounts with respect to Ni loading; the amount of protodetriflation observed was also dependent on substrate and reaction time.

${ }^{21}$ The treatment of 1-arylvinyl triflates with $\mathrm{LiCl}$ results in a competitive, nonNi-mediated elimination to afford the aryl acetylenes. Yang, D. Wu, Z. Lu, H. Sun, A. Li, Org. Biomol. Chem. 2016, 14, 5591-5594.

${ }^{22}$ Addition of exogenous cod inhibits the rate of the reaction, indicating that ligand dissociation could be the source of the induction period.

${ }^{23}$ D. G. Blackmond, J. Am. Chem. Soc. 2015, 137, 10852.

${ }^{24}$ No evidence of oxidative addition is observed when enol triflate $1 \mathrm{a}$ and $\mathrm{Ni}(\mathrm{cod})_{2}(5 \mathrm{~mol} \%)$ were mixed in the presence or absence of NaOTf. However, upon addition of a metal halide salt, conversion of $\mathbf{1 a}$ to the alkenyl halide (2a-c) was observed concomitantly with the formation of a $\mathrm{Ni}(\mathrm{I})-\mathrm{X}$ species. The same $\mathrm{Ni}(\mathrm{I})-\mathrm{X}$ species were detected upon mixing $\mathbf{2 a}$ c and $\mathrm{Ni}(\operatorname{cod})_{2}(5 \mathrm{~mol} \%)$. Oxidative addition of aryl triflates to (dppf)Ni(cod) was previously shown to form $\mathrm{Ni}(\mathrm{I})$ complexes: S. Bajo, G. Laidlaw, A. R. Kennedy, S. Sproules, D. J. Nelson, Organomet. 2017, 36, 1662-1672. (b) I. Kalvet, Q. Guo, G. J. Tizzard, F. Schoenebeck, ACS Catal. 2017, 7, 2126. ${ }^{25}$ Relevant mechanistic studies: M. M. Beromi, A. Nova, D. Balcells, A. M. Brasacchio, G. W. Brudvig, L. M. Guard, N. Hazari, D. J. Vinyard, J. Am. Chem. Soc. 2017, 139, 922.

${ }^{26}$ The reaction was sampled every 5 minutes, but at no time was enol triflate 25-OTf detected. 
